\title{
Manufacturing in the time of COVID-19: An Assessment of Barriers and Enablers.
}

\author{
Okorie O., Ramesh, S., Charnley F., David W., Patsavellas J., Salonitis, K.,
}

\begin{abstract}
Pandemics and other forms of epidemic outbreaks are a unique case of manufacturing risk typified by high uncertainty, increasing propagation and long-term disruption to manufacturers, supply chain actors as well as the end-users and consumers. For manufacturing the COVID-19 disruption scope has been largely two-fold; an endogenous disruption of manufacturing processes and systems as well as extreme shifts in demand and supply caused by exogenous supply chain disruption. Existing literature on disruptions in manufacturing suggests that pandemics are qualitatively different from typical disruptions. There is no literature available to manufacturing practitioners that identify the barriers and enablers of manufacturing resilience, especially with regards to pivoting of the manufacturing sector in response to a pandemic. This study draws on an extensive survey collected during the COVID-19 pandemic. The respondents were employees of manufacturing firms in all regions of the world who had engaged in manufacturing during the pandemic or had opted out from manufacturing due to various identified reasons. By collating their responses, we offer to practitioners and policymakers an analysis for identifying a bestpractice framework for pivoting successfully as a response to major manufacturing disruptions.
\end{abstract}

Index Terms-manufacturing, manufacturing resilience, COVID-19, coronavirus, pivoting, digital technologies, pandemic, supply chain disruption.

\section{INTRODUCTION}

$\mathrm{F}$ IRST reported in Wuhan, Hubei province, China in December 2019, the novel Coronavirus disease increased in its number of cases and rapidly swept across the globe, straining healthcare facilities, supply chains and manufacturing production lines.

Johns Hopkins University's Coronavirus Resource Centre on June $20^{\text {th }}, 2020$ confirmed over 8.62 million infections and over 485,706 deaths globally [1]. While these estimates suggest that the Coronavirus-also known as COVID-19-is less infectious than the SARS (severe acute respiratory syndrome) or MERS (Middle East respiratory syndrome), it has proved more pervasive in its spread when compared to other large-scale outbreaks [2].

In its assessment, the World Health Organization (WHO) declared the flu outbreak as a pandemic on March 11, 2020. As a result of border closures and other pandemic restrictions, economic decline became global. US industrial production recorded its biggest monthly decline since the end of World
War II while business activity across the Eurozone collapsed to a record low in March 2020 [3].

Beyond pandemics and epidemics, manufacturing and supply chains have experienced large-scale disruption due to natural disasters and political risks. The impact of the 2011 tsunami event on the Japanese car manufacturing industry led to closures of Sony, Toyota and Nissan factories in Japan and the United Kingdom. The US-China "Trade War", with its highest impact in 2019, caused many Chinese manufacturers to shift production facilities to other parts of South East Asia [4]. Car sales in the UK experienced its worst month since 1946 in April 2020 , as sales fell by $97 \%$ [5].

Overall, statistics show that disruptions caused by unexpected and catastrophic events are increasing and organizational disruptions are at their highest. Traditionally, servitization, the shift from a product-centric to a service-centric business model and logic, has helped manufacturing firms to stabilize their firms in the face of disruption [6]. Despite the availability of such options, manufacturing is expected to be one of the most severely affected sectors in terms of the negative economic impact [7]. This outcome is due to the sheer scale of the crisis and the extreme methods taken to mitigate it.

Some manufacturing firms took responsibility for supplying critical equipment and devices needed by the public and medical institutions. Specifically, repurposing and pivotingthe process of manufacturers rapidly switching to a new product or process - has been successfully implemented by some manufacturers. Many found it challenging to repurpose.

This study assesses survey responses from 71 manufacturing practitioners across North America, Europe, Asia, South America and Africa. We identify the enablers and barriers of manufacturing repurposing within the context of disruption caused by COVID-19. We establish the assumption that these enablers and barriers are similar across regions as long as the context is restricted to manufacturing firms and pandemic disruption.

Employees who were closely involved in manufacturing or related services - at the strategic and operational level—were invited to participate in completing the online survey. We provide insights for other large-scale disruption situations facing manufacturers and industry practitioners. Important 
lessons for manufacturing and supply chains exist and are presented.

\section{Manufacturing and the Pandemic}

The virus outbreak has prompted studies across many disciplines. Within manufacturing the emergent research covers a range of subjects, including the role of additive manufacturing in managing COVID-19; the impact of COVID-19 on manufacturing via country-specific case studies; resilience and manufacturing supply chain risks for high-demand items; Industry 4.0 technologies, applications and tools essential in the management of COVID-19 cases.

The number of studies suggests that manufacturing is an essential pandemic management concern. This manufacturing concern includes mass production of WHO-identified personal protection equipment (PPE) and other medical equipment [8$10]$.

Italian manufacturing firms was examined by academics in Italy, Sweden and Finland in an extensive survey of 177 respondents distributed across SMEs and across large companies. Their study focused on comparing the impact of the disruption caused by the pandemic on product and service businesses in order to develop a crisis-management model [11]. The impact of low-tech manufacturing solutions argued that solutions need to coalesce around approved designs to have a real impact [12]. Other studies examine manufacturing from the perspective of supply chain resilience and risks [13,14]. There is a clear critical role manufacturing has to play in managing the pandemic.

No studies identify the supporting enablers and the impeding barriers to manufacturing under a COVID-19-like environment. Many national and regional bodies identified repurposing of manufacturing as a way for manufacturers to meet increased demands for medical equipment and PPE. These include the European Commission ${ }^{1}$, the United Kingdom as expressed in the Ventilator Challenge UK program [15] and United Nations Industrial Development Organization (UNIDO) [16].

Manufacturing repurposing includes adapting production plans, lines and capabilities including $R \& D$ capabilities to meet new demand goals. Within the pandemic disruption context, manufacturing repurposing becomes a more important strategy. A United States study, for example, estimates that over 2,700 manufacturing facilities owned by large firms could be repurposed to product COVID-19 critical items in the US [17]. While advantageous, manufacturing repurposing is a temporary strategy and can be expensive. This study therefore seeks to ask

\footnotetext{
1 On May 19, 2020 the European Commission released a funding opportunity call for repurposing of manufacturing of vital medical supplies and equipment. Website: https://ec.europa.eu/info/fundingtenders/opportunities/portal/screen/opportunities/topic-details/sc1-phecoronavirus-2020-2a
}

these broad questions: How successful is manufacturing repurposing as an essential pandemic management tool? What are the barriers and enablers for repurposing in the context of large scale disruption? and What lessons are there for future disruptions?

The next section briefly introduces the methodology employed for this study.

\section{METHODOLOGICAL APPROACH}

This study was completed between June and July 2020. We assumed that the barriers and enablers were similar across the world.

An on-line survey method was chosen to acquire data. We also included practitioners involved in delivering manufacturing related services-including manufacturing consultancies, and supply chain professionals - to obtain a more robust result. The survey results also help identify the recommendations for practitioners as they adapt to the so-called "next normal" as well as plan for future large-scale disruptions. For example, there is an expectation of a second subsequent Coronavirus wave of infection. The sample represents 71 respondents across 39 manufacturing firms and non-manufacturing firms; but who were working with these firms.

The electronic survey included identifying the kinds of manufacturing industries globally available. For these categorizations we used the American Enterprise Institute ${ }^{2}$ website which had developed a tableau interface for corporate responses to Covid-19; manufacturing industries were also identified from the Institution of Engineering and Technology $\left(\right.$ IET) ${ }^{3}$ website. We thus identified 39 manufacturing industries. We identified 13 countries based on the pandemic spread and growth from the Johns Hopkins University's Coronavirus Resource Centre and gave allowance for other countries to ensure a global outlook. Our survey also captured nonmanufacturing industries as we attempted to track their enablers and barriers to operations during the disruption.

A survey of 19 questions included closed and opened-ended questions. Sixteen (16) enablers and sixteen (16) barriers of manufacturing were identified from the literature [11,18-20]. Respondents were allowed to choose multiple barriers and enablers and were also allowed to specify barriers and enablers which were not present in the survey. Respondents were also allowed to specify if they operated or were not operating during the pandemic as well as the degree of operations.

To increase the robustness and the detail of the study, respondents were allowed to detail manufacturing events. For

\footnotetext{
${ }^{2}$ The American Enterprise Institute have continued to capture the Corporate Responses to COVID-19 in a tableau format from 14.04.2020. Website: https://public.tableau.com/profile/american.enterprise.institute5522\#!/vizhome /Eaglencompanies1/Dashboard1

3 The Institution of Engineering and Technology (IET). Website: https://www.theiet.org/
} 
example, open ended questions such as, "briefly explain how any of your manufacturing processes have been affected"; "please explain briefly if and how your existing product lines/supply services have been affected".

The survey also captured impact of innovation and sustainability concerns as influential organizational measures for firms during the COVID-19 pandemic. The survey was developed on the Qualtrics interface and communicated to respondents via email.

\section{RESULTS AND DISCUSSION}

Our sample of 71 respondents - across 39 facilities - and 6 continents (Europe, Africa, North America, South America and Asia). All respondents were given the opportunity to offer open-ended responses and some of their responses are provided in this section. Figure 2 gives the graphical representation of these locations.

Figure 1: Location of manufacturing facilities.
Location of manufacturing facilities

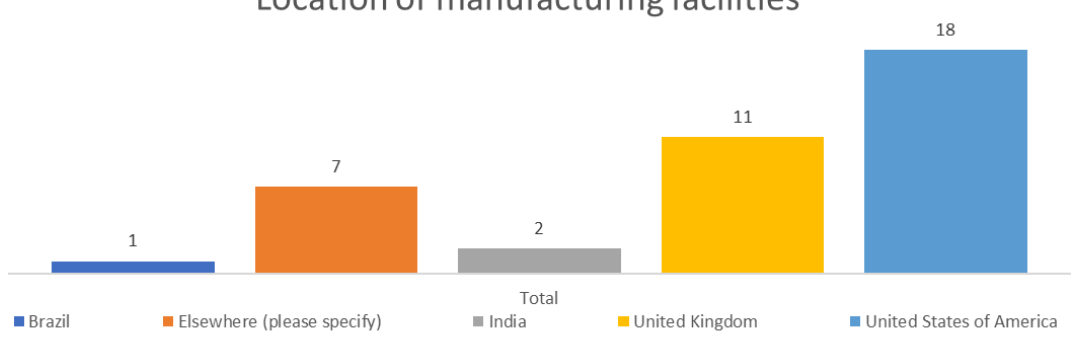

We observe that multiple manufacturing firms had repurposed during the pandemic. Target products included respirators and their components, medical PPE—surgical masks, clinical care equipment, examination gloves, and eye protection, googles and face shields - and hand sanitizers.

Repurposing was less likely and did not occur for several product families. These products included mobile X-rays, clinical care equipment, medical helmets, surgical gloves, screening test kit and other diagnostic equipment.

Respondents cited "organizational flexibility" (24), "employee skills and know-how (23)", and "technological ability and capacity/ digital technologies (22) as the three top enablers for manufacturing and manufacturing repurposing.

Organizational flexibility refers to broader organizational concerns, not necessarily manufacturing. Service-based settings had organizational flexibility as a core organizational objective. Different parameters were introduced to address uncertainties and contingencies. Manufacturers swiftly introduced flexible working by varying shift patterns and flexed their sourcing with alternative suppliers and supply routes in order to accommodate the disruption. Organizational flexibility is identified as a key factor driving the success of dynamic organizations $[21,22]$.

Manufacturing firms possessing employees with a diverse level of skillsets were better suited for manufacturing repurposing. Respondents noted that social distancing and the consequent limited number of people on-site forced a reduction in the number of employees on-site.

"Elsewhere" includes respondents from China, Nigeria, Estonia, Greece, Mexico and Hungary. The US and the UK represent over $74 \%$ of these locations. This is due to multiple reasons, which includes the accessibility of research team to manufacturers and manufacturing practitioners within the US and UK (on the basis of proximity) as well as the COVID-19 levels of both countries that required a robust manufacturing involvement.

Almost all organizations were operational during the peak of the pandemic (94\%) either at full $(56 \%)$ or partial operations (44\%) capacity. Respondents had valid insight for identifying the enablers and barriers in manufacturing.

Respondent industries included fast moving consumer goods, computers, electronic and optical products - these industries displayed the highest ability in manufacturing repurposing. Pharmaceutical industries and the leather industries were the least likely to repurpose.

\subsection{MANUFACTURING AND REPURPOSING ENABLERS}

\footnotetext{
${ }^{4}$ These comments were extracted from the data sheet without any form of editing implemented.
}

We provide a couple social distancing comments that support the need to have fewer employees present ${ }^{4}$.

Respondent A: "Our operations required staff to keep a space of $6 \mathrm{ft}$ apart and wearing a mask at all times. We kept the production floor spread out, so less employee interaction.

Respondent B: Covid-19 prevented workers from going to the office. Traditionally, developers use secured network and work stations to develop software for clients. We were forced to come up with a new working model, where office equipment was shipped to homes and VPNs were established overnight to continue development. There was an initial impact in terms of throughput, however we observed that actual throughput increased gradually over the period of time as employees got used to the new setup.

Figure 2 presents the responses across various enablers as identified in the survey. 
Several respondents (15) noted that their manufacturing lines

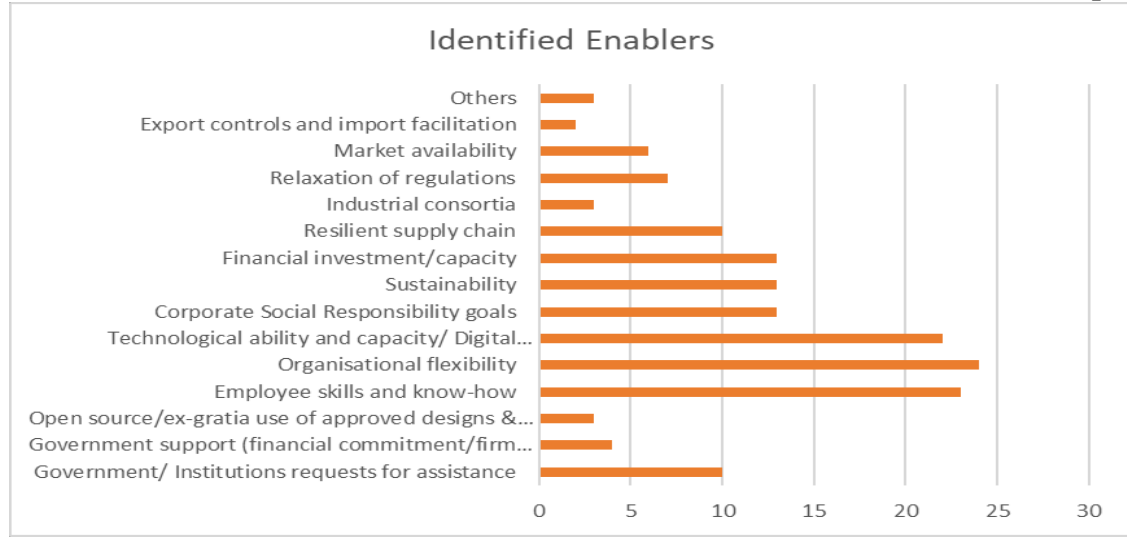
were impacted by the pandemic and lockdown through increased demand for their types of products. We categorize this as a barrier, as these firms did not—and could notrepurpose.

Other important barriers include financial constraints caused by increased cost in repurposing (10); time constraints (8); safety and regulatory concerns (7); and lack of appropriate skillset to support repurposing.

A UNIDO report also observes several of these Figure 2: Manufacturing enablers identified in survey responses.

barriers [16]. Beyond these identified barriers, current literature argues that firms which operate or support their operations with servitized business models - including leasing and renting of products - are more resilient than traditional models purely Technological ability, capacity and digital technologies were also mentioned as a key enabler for manufacturing and manufacturing repurposing. The use of digital technologies have been highlighted as crucial in flattening the curve as manufacturers were able to redesign and repurpose faster [15,16,23].

Manufacturing and supply chain disruption occur less often when managed with digital twins and can improve post-pandemic recoveries [14].

Many respondents highlighted the important role these technologies played in working from home, while supporting fewer on-site employees.

As one respondent stated: “digital technologies helped alter workspace layout, drive new work-from-home policies, supported conferencing tools and lead to a speedier manufacturing”.

Respondents identified other key enablers including: corporate social responsibility goals (13), financial investment- capacity to manage repurposing (13), and manufacturing repurposing as a contributor to sustainability (13).

We note that these enablers are complementary as several respondents identified multiple enablers within a single manufacturing facility. Thus, manufacturing firms embracing multiple enablers is likely to increase manufacturing resilience.

\subsection{MANUFACTURING AND REPURPOSING BARRIERS}

We identify several barriers to manufacturing and manufacturing repurposing during the pandemic as shown in Figure 3. Only $6 \%$ of the manufacturing firms identified-just 2 respondents-were not operational during the early periods of the pandemic. All respondents were invited to identify manufacturing barriers. focused on selling products [12]. Fluctuating demand and supply was also identified as a barrier by respondents. The next section provides some recommendations for manufacturing

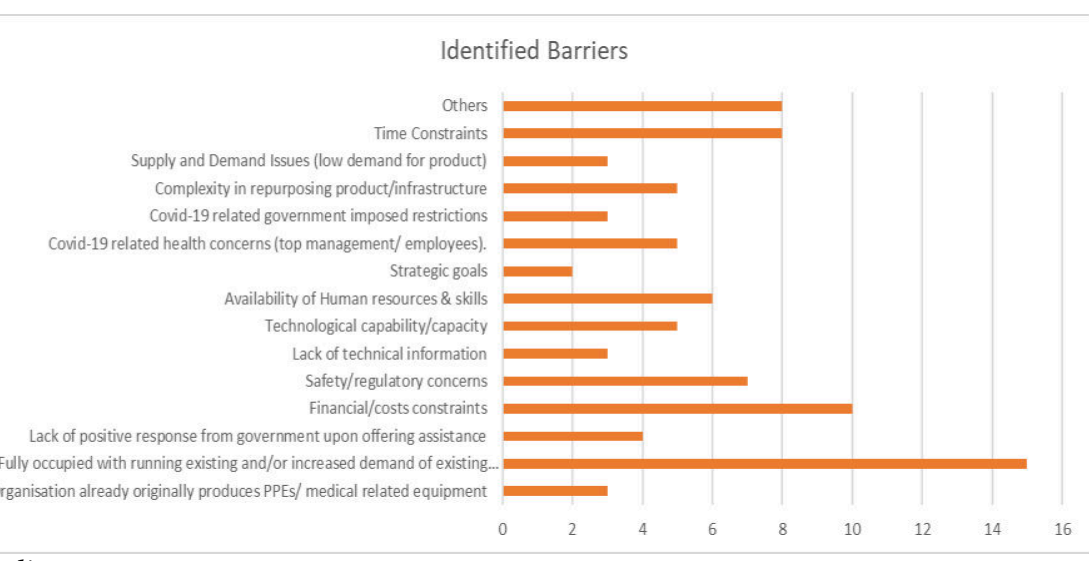

practitioners and managers based on these findings.

Figure 3: Manufacturing and repurposing barriers identified by respondents

\section{CONCLUSIONS \& RECOMMENDATIONS}

Given that as of this writing, the COVID crisis continues and is a rapidly evolving phenomenon, available evidence currently shows that the manufacturing response to the disruption has been largely reactive and uncoordinated [24].

Moreover, despite the increasing number of disruptions caused by epidemics, natural disasters and other large-scale regional and global events, many firm crises communication plans do not specifically include managing an infectious disease outbreak [25]. There is little doubt that the inability to manufacture especially critical equipment and products would be detrimental in fighting the pandemic and ensuring a return back to normalcy.

A vast majority of the professionals surveyed are in agreement that the downtime in manufacturing can also affect the overall 
well-being of employees and their future outlook. For many manufacturing firms, operations have either continued remotely or have been constrained by the new health guidelines, whether working at full or limited capacity. From our analysis of the manufacturing enablers and barriers, we make the following recommendation for ensuring pandemic and post-pandemic manufacturing capabilities and operations:

\section{Re-Jigging of Manufacturing Toolboxes:}

Traditional manufacturing "toolboxes" do not offer best-practice frameworks that can be used for structured approaches in preparing for and responding to disruptive events. The lean toolbox provides blueprints for achieving value at the lowest possible cost by maximizing flows in stable demand conditions; whilst the agile paradigm with decoupling points, caters mainly for responsiveness to demand fluctuations on existing product lines. This situation has in many cases resulted in reactive planning and deadlocked schedules of production with manufacturing operations detrimentally affected. For example, Scania - a vehicle manufacturer - has had to temporarily close its manufacturing facilities for over three weeks, and may not return to full production capacity until 2021. An updated toolbox should be created to enable manufacturers to prepare for higher levels of resilience that account for the needs of pivoting and repurposing, by incorporating a systematic factoring of the identified key challenges, barriers and opportunities for manufacturing. For maximum impact such a toolbox would need to be tailored to the specific industrial sector and regional context of each enterprise with a holistic engagement of its supply network.

2. Building Organisational Flexibility: We identified that several manufacturers and service-sector providers were successful in weathering the pandemic crisis. For example, the Volvo Group did not report any fluctuation in service revenue in the first quarter of 2020-- which was near the peak months of the disruption, March -2020. Organizational flexibility was highlighted as the key reason for manufacturing firms to continue manufacturing - either as normal or through manufacturing repurposing. Organizational flexibility may include actions such as setting up work at home capabilities, redesigning office and manufacturing space for social distancing, access to appropriate technology for remote working, and an expansion of sourcing portfolios. These are multiple levels of flexibility and are comprehensive. Robust flexibility may vary from sector to sector; and even industry to industry. Regulatory, compliance and emergency legislation factors may however affect such flexibility from sector to sector or even country to country.

3. Digital Technology: The uptake of digital technologies within manufacturing has become increasingly pervasive as manufacturers gradually move from a low-cost business model to one which is primarily premised on value. The President of a major aerospace manufacturing company in the US stated: "We need to trace supply chain visibility beyond the Tier 1 supply base and digital tools can provide traceability beyond Tier 1 to the entire supply network to understand supply side risk. The company also leveraged additive manufacturing to produce thousands of PPE products such as handsfree door openers and face shields for their employees and the medical community".

Our study shows that manufacturing firms with a high level of digitization - in production facilities and helping in employee skills - display higher resilience and adaptability than manufacturers with lower digital adoption. Accelerating the digital transformation of manufacturing can increase visibility of pivoting and collaboration opportunities, with investment in digital upskilling becoming a serious prerequisite.

4. Rapid Decision-Making: Manufacturing firms who were able to make decisions much quicker were found to be more responsive during the pandemic. For example, commissioning new technologies quickly to enable both in-house and contract staff to work from home, were seen to have supported manufacturing processes more efficiently. For a particular manufacturer during the early stages of the pandemic growth, rapid decision-making enabled them to saturate their existing market and expand to new ones. Thus, the pandemic accelerated growth plans within their operating region.

Practitioners must ensure the availability and development of the necessary information systems, rapid analytical capability, and protocols to enable a culture and structure of rapid, and delegated decisionmaking. This effort may require organizational change programs with substantial leadership drive, effort and resources to effect it.

\section{Identifying and Dedicating Resources for} Repurposing: One of the largest barriers we observed is the lack of appropriate and dedicated financing and resource allocation for repurposing. The lack of such planning has proved to be a lost opportunity for many organizations and may be explained by the attitude towards opportunity cost reduction in risk provisioning. The wisdom of strategic task production focus needs to be reexamined in light of lessons learned and the ability to flex production assets from a focused-factory to a reconfigurable factory. This capability should be considered as an important capital budgeting criterion. 
Industry 4.0 technologies that can enable such multipurpose and re-purpose manufacturing will require prioritization. Repurposing investments could also be considered long-term investments in potentially new product markets for potential long-term benefits.

6. Benchmarking: We identified similarities across industrial sectors in their response to the disruption; responses included operational changes as well as the changes in product line. Reflections from respondents within these organizations suggests that these changes and implementation were considered strictly within individual organizations. We propose benchmarking be effectively completed. This is the process of evaluation of organizational products, services and processes in relation to best practice [26]. The efficiency of this tool can be seen in the success of the VentilatorChallenge UK program. We propose a cross-industry benchmarking exercise given the similarities we observed across industrial sectors. Sharing and learning across industrial sectors is an important continuous improvement tool for manufacturing this pandemic; but also in other disruptive situations.

Overall, there is promise in mitigating the immense pandemic crisis disruption in manufacturing. Some of the key enablers and barriers are introduced in this paper. While we offer recommendations to industry practitioners, we concede that the industry sectors are subject to external factors-such as national or regional policy, new or previously unseen shocks in the supply chain - which can change the internal processes of businesses. These geographical idiosyncratic situations are not captured fully in our recommendations. Further research should investigate related nuances associated with specific manufacturing sectors taking into account the caveats of implementation in the context of different countries and geographic regions.

The lessons learned in this study set a baseline for future disruptions and occurrences. It is not clear if similar enablers and barriers will be observed, but we believe there will be significant commonalities with other disruptions. Building a flexible manufacturing environment that is resilient should mean managing with enablers and barriers in mind.

\section{ACKNOWLEDGMENT}

Okorie is grateful to the UK Engineering and Physical Sciences Research Council No. EP/R032041/1 who allowed him time to work on this study. The authors are also grateful to Maja Miceli who supported with the reviewing of the analysis. Finally, the authors are grateful to every respondent who completed the electronic survey.

\section{AUTHORS LIST}

Okechukwu Okorie is currently a Postdoctoral Research
Associate with the Exeter Centre for Circular Economy, Exeter Business School, University of Exeter. His research interests include circular economy, smart remanufacturing, data-driven decision making and simulation modelling of manufacturing systems.

Ramesh Subramoniam is currently a Clinical Associate Professor with the Naveen Jindal School of Management, University of Texas at Dallas. His research interests includes digital supply chains and reverse logistics.

Fiona Charnley is currently an Associate Professor of Circular Economy and Co-Director Exeter Centre for the Circular Economy and researches on circular design and manufacture, data-driven decision making, self-healing materials.

John Patsavellas is currently a Senior Lecturer in Manufacturing Management and a member of the IET's Manufacturing Policy Panel and IET's Production and Design Sector. His expertise includes design, strategy \& innovation, smart materials, sustainable manufacturing, product and service design.

David Widdifield is Assistant Dean, Graduate Programs and Clinical Associate Professor with the Jindal School of Management, The University of Texas, Dallas with research interests in supply chain risk management and resiliency.

Salonitis Konstantinos is a Professor and Head, Sustainable Manufacturing Systems at Cranfield University having research interest in sustainable manufacturing, manufacturing systems and product and service Design.

\section{REFERENCES}

1. Johns Hopkins University \& Medicine. COVID-19 Dashboard by the Center for Systems Science and Engineering (CSSE). 26 April 2020. 2020. Available at: https://coronavirus.jhu.edu/map.html (Accessed: 20 June 2020)

2. Callaway BE., Cyranoski D., Mallapaty S., Stoye E., Tollefson J. Coronavirus by the numbers. Nature. 2020; 579: 482-483.

3. Badkar M., Greeley B. New data shows vast scale of US economic breakdown. Financial Times. 2020. Available at: https://www.ft.com/content/6361247d-a1df-4a50-b0aa59395801b3f3 (Accessed: 15 April 2020)

4. Kajitani Y., Chang SE., Tatano H. Economic Impacts of the 2011 Tohoku-oki earthquake and tsunami. Earthquake Spectra. 2013; 29(SUPPL.1): 457-478. Available at: DOI:10.1193/1.4000108

5. Campbell P. UK car sales fall $97 \%$ in worst month since 1946. Financial Times. 2020. pp. 1-2. Available at: https://www.ft.com/content/a97e0730-d94f-4b64-89c99c0a410f9281

6. Kowalkowski C., Kindström D., Alejandro TB., Brege S., Biggemann S. Service infusion as agile incrementalism in action. Journal of Business Research. Elsevier Inc.; 2012; 65(6): 765-772. Available at: DOI:10.1016/j.jbusres.2010.12.014

7. ILO. COVID-19 and the world of work. 2020; (May): 1-24. Available at:

https://www.ilo.org/wcmsp5/groups/public/@dgreports/@dcomm/d ocuments/briefingnote/wcms_743146.pdf

8. Prather KA., Wang CC., Schooley RT. Reducing transmission of SARS-CoV-2. Science. 2020; 6197: eabc6197. Available at: 
DOI:10.1126/science.abc6197

9. Kis Z., Kontoravdi C., Dey A., Shattock R., Shah N. Rapid development and deployment of high-volume vaccines for pandemic response.pdf. Journal of Advanced Manufacturing and Processing. 2020;

10. Blake R. Advanced Manufacturing's Moment: Making Supplies for the War on COVID-19. Forbes. 2020. Available at: https://www.forbes.com/sites/richblake1/2020/04/03/advancedmanufacturings-moment-making-supplies-for-the-war-on-covid19/\#1e6037642d1b

11. Rapaccini M., Saccani N., Kowalkowski C., Paiola M., Adrodegari F. Navigating disruptive crises through service-led growth: The impact of COVID-19 on Italian manufacturing firms. Industrial Marketing Management. Elsevier; 2020; 88(May): 225-237. Available at: DOI:10.1016/j.indmarman.2020.05.017

12. Armani AM., Hurt DE., Hwang D., McCarthy MC., Scholtz A. Low-tech solutions for the COVID-19 supply chain crisis. Nature Reviews Materials. Springer US; 2020; 5(June): 403-406. Available at: DOI:10.1038/s41578-020-0205-1

13. T L., B V. Coronavirus is proving we need more resilient supply chains. Harward business review. 2020; Available at: https://hbr.org/2020/03/coronavirus-is-proving-that-we-need-moreresilient-supply-chains

14. Ivanov D., Dolgui A. A digital supply chain twin for managing the disruption risks and resilience in the era of Industry 4.0. Production Planning and Control. Taylor \& Francis; 2020; 0(0): 1-14.

Available at: DOI:10.1080/09537287.2020.1768450

15. Microsoft UK. 20 years to 12 weeks: British manufacturers unite to build ventilators for the NHS. 2020.

16. López-Gómez C., Corsini L., Leal-Ayala D., Fokeer S. COVID-19 Critical Supplies: The Manufacturing Repurposing Challenge. United Nations Industrial Development Organization. 2020; : 1-7. Available at: https://www.unido.org/news/covid-19-criticalsupplies-manufacturing-repurposing-challenge

17. Ambrosio N. Responding to the COVID-19 Crisis: Can Industry Help? - Four Twenty Seven. 2020. Available at: http://427mt.com/2020/03/26/responding-to-the-covid-19-crisiscan-industry-help/?mod=article_inline

18. Belton KB. COVID-19 Makes the Case for Resilient Manufacturing. Industry Week. 2020. Available at: https://www.industryweek.com/the-economy/publicpolicy/article/21129255/covid19-makes-the-case-for-resilientmanufacturing (Accessed: 17 June 2020)

19. Brown N. Is it Time to Rethink Globalized Supply Chains? MIT Sloan Management Review. 2020; 26(2): 141-142. Available at: DOI:10.1093/spp/26.2.141

20. De' R., Pandey N., Pal A. Impact of digital surge during Covid-19 pandemic: A viewpoint on research and practice. International Journal of Information Management. Elsevier; 2020; (June): 102171. Available at: DOI:10.1016/j.ijinfomgt.2020.102171

21. Ahrens T., Chapman CS. Accounting for Flexibility and Effiency: A Field Study of Management Control Systems in a Restaurant Chain. Contemporary Accounting Research. 2004; 21(2): 271-301. Available at: DOI:10.1506/VJR6-RP75-7GUX-XH0X

22. Brown P., Ly T., Pham H., Sivabalan P. Automation and management control in dynamic environments: Managing organisational flexibility and energy efficiency in service sectors. British Accounting Review. Elsevier Ltd; 2019; 52(2): 100840. Available at: DOI:10.1016/j.bar.2019.100840

23. Büchi G., Cugno M., Castagnoli R. Smart factory performance and Industry 4.0. Technological Forecasting and Social Change. Elsevier; 2020; 150(October 2019). Available at: DOI:10.1016/j.techfore.2019.119790

24. Taleb NN., Norman J., Bar-Yam Y. Systemic Risk of Pandemic via Novel Pathogens - Coronavirus: A Note. New England Complex Systems Institute. 2020. Available at: http://arxiv.org/abs/1410.5787 25. Peppercoomm., Institute for Public Relations. How Businesses are Handling the Crisis. 2020; : 1-9.

26. Callam JA. Jack A. Callam. 1993; 31: 141-143.

28. Dun \& Bradstreet Study 2020 https://www.cnbc.com/2020/02/17/coronavirus-could-impact-5$\underline{\text { million-companies-worldwide-research-shows.html }}$ 


\section{Manufacturing in the time of COVID-19: an assessment of barriers and enablers}

Okorie, Okechukwu

IEEE

Okorie O, Ramesh S, Charnley F, et al., (2020) Manufacturing in the time of COVID-19: an assessment of barriers and enablers. IEEE Engineering Management Review, Available online 27 July 2020

https://doi.org/10.1109/EMR.2020.3012112

Downloaded from Cranfield Library Services E-Repository 